\title{
BSA-based sample clean-up columns for ochratoxin A determination in wine: Method development and validation
}

\author{
Tânia Leal, Luís Abrunhosa, Lucília Domingues, Armando Venâncio, Carla Oliveira* \\ CEB - Centre of Biological Engineering, University of Minho, 4710-057 Braga, Portugal
}

\section{A R T I C L E I N F O}

\section{Keywords:}

Ochratoxin A

Bovine serum albumin

Solid-phase extraction

Wine analysis

Method validation

\begin{abstract}
A B S T R A C T
Analytical chromatographic techniques for mycotoxins control are well established, but they often depend on costly immunoaffinity sample clean-up. Serum albumins, particularly that from bovine origin (BSA), have stable binding affinity towards some mycotoxins, and can be cheaper alternative receptors for sample clean-up due to their wide availability. Thus, this work used BSA immobilized in agarose beads as a novel solid-phase extraction method for quantification of ochratoxin A (OTA) in wine. Constructed BSA-agarose columns could extract OTA efficiently from red wine after its dilution (4-fold) in $0.1 \mathrm{M}$ Tris $\mathrm{pH}$ 8.0. The method was linear $\left(\mathrm{R}^{2}=0.9999\right)$ in the OTA concentration range studied $\left(0.05\right.$ to $\left.3.0 \mu \mathrm{g} \mathrm{L}^{-1}\right)$, with recovery rates above $98 \%$. It also showed low detection $\left(0.017 \mu \mathrm{g} \mathrm{L}^{-1}\right)$ and quantification $\left(0.051 \mu \mathrm{g} \mathrm{L}^{-1}\right)$ limits. The efficacy of the BSA-based method was further validated by direct comparison with commercial immunoaffinity columns. Portuguese wines analyzed by both methods had agreeing results.
\end{abstract}

\section{Introduction}

Ochratoxin A (OTA) is a widely spread mycotoxin which is produced by fungi belonging to the genera Aspergillus and Penicillium (Sorrenti et al., 2013). Ochratoxigenic fungi can grow in various food crops and consecutively cause the accumulation of this mycotoxin in animal feedstuffs and human food such as cereals-based products, coffee, dried fruits, beer, wine, meat, among other (Koszegi \& Poor, 2016). Due to its nephrotoxic, mutagenic, teratogenic, neurotoxic, hepatotoxic and immunotoxic properties, the ingestion of food contaminated with OTA is considered a severe problem since it can deeply affect human and animal's health (Bennett \& Klich, 2003). These effects are visible not only after a single heavy exposure but also, and most commonly, after continuous exposure to low doses of this toxin (Reddy \& Bhoola, 2010). In addition, according to the International Agency for Research on Cancer (IARC), OTA is classified as Group 2B carcinogen (possibly carcinogenic to humans) (IARC, 1993).

Wine is a widely consumed beverage and represents one of the biggest sources of OTA daily intake in some countries (Miraglia \& Brera, 2002). For example, in Portugal, wine contributes for $8 \%$ of the probably daily intake of OTA (Abrunhosa et al., 2016). Thus, the European Commission fixed the regulatory limit of OTA in wine, grape juices and grape beverages at $2 \mu \mathrm{g} \mathrm{Kg}^{-1}$ (EC, 2016). Therefore, to meet this regulation, and assure consumer's health, there has been a constant need to monitor OTA concentration in these beverages.

The most used technique to quantify OTA is high performance liquid chromatography (HPLC) coupled with fluorescence detection (FL), which is considered a fast, reliable and sensitive method for OTA detection. However, in order to reach low quantification limits, and more precise and accurate results, a previous step of sample clean-up and concentration is usually necessary. Presently, this step is mainly performed with immunoaffinity columns (IACs), but despite providing reliable results they still have important drawbacks. The most important of them are related to matrix interference, cross reactivity, column capacity, column's short life, and, most important, to the high cost of these columns (Castegnaro et al., 2006; Senyuva \& Gilbert, 2010). All these disadvantages motivate the development of alternative methods that could be more cost-effective and at least as robust, precise and accurate as IACs. Thus, research has focused on the development of synthetic systems that mimic the recognition properties of antibodies (mainly aptamers, peptides and molecular imprinted polymers), in order to replace them in sample clean-up columns (Baggiani, Giovannoli, \& Anfossi, 2015; Huertas-Pérez, Arroyo-Manzanares, García-Campaña, \& Gámiz-Gracia, 2017; Pichon \& Combès, 2016). Furthermore, significant advances have been made in the field of biosensors for mycotoxin analysis to replace conventional

\footnotetext{
* Corresponding author at: CEB - Centre of Biological Engineering, Universidade do Minho, Campus de Gualtar, $4710-057$ Braga, Portugal.

E-mail addresses: luisjap@deb.uminho.pt (L. Abrunhosa), luciliad@deb.uminho.pt (L. Domingues), avenan@deb.uminho.pt (A. Venâncio), carlaoliveira@deb.uminho.pt (C. Oliveira).
} 
chromatographic and ELISA techniques. Research trend is towards the selection of improved synthetic receptors (Bazin, Tria, Hayat, \& Marty, 2017), transduction strategies (e.g. electro-chemical, optical), miniaturization (e.g. lab-on-chip, microfluidic), development of novel sensing materials (e.g. functionalized nanoparticles), design of signal generation (labelled and label free techniques), with the objective of lowering the detection limits (up to $\mathrm{pg} / \mathrm{mL}$ ), broadening linear range of quantification and enhancing sensor shelf-life (Chauhan, Singh, Sachdev, Basu, \& Malhotra, 2016). Despite these research efforts, the immunochemical and chromatographic-based analytical techniques are in the forefront of detection of regulated mycotoxins in food commodities (Anfossi, Giovannoli, \& Baggiani, 2016).

Serum albumins are known to form stable complexes with mycotoxins, including OTA, being responsible for their transport and toxicity within the body (Ringot, Chango, Schneider, \& Larondelle, 2006). The higher binding constant for OTA-albumin interaction was identified for human serum albumin (HSA) $\left(5.2 \times 10^{6} \mathrm{M}^{-1}\right)$ (Il'ichev, Perry, Ruker, Dockal, \& Simon, 2002), followed by bovine serum albumin (BSA) $\left(3.2 \times 10^{5} \mathrm{M}^{-1}\right)$ (Chu, 1974). Structurally, albumins are composed of three globular domains, each of them containing two subdomains (subdomains IA and IB; IIA and IIB; IIIA and IIIB) (Carter \& He, 1990). It has been shown that the primary OTA binding site is located in subdomain IIA (Sudlow's Site I), but a secondary OTA binding site that has much less affinity for the mycotoxin has also been identified in subdomain IIIA (Sudlow's Site II) (Il'ichev, Perry, \& Simon, 2002). Although mycotoxin-albumin interactions have been extensively investigated in recent years (Koszegi \& Poor, 2016), albumins have not yet been employed with success as capturing agents of mycotoxins from food matrixes for analytical purposes, as far as we known.

In the present study, we take advantage of the binding affinity of BSA to OTA, to develop a new solid phase extraction (SPE) method to capture, concentrate and clean OTA from wines for posterior HPLC-FL quantification. Columns packed with agarose containing immobilized BSA were validated for the analysis of OTA in red wine and the results obtained were compared with that resulting from commercial IACs.

\section{Materials and methods}

\subsection{Materials and chemicals}

Cyanogen bromide-activated agarose (C9210) and an OTA standard (O1877-5MG) were obtained from Sigma-Aldrich (Sintra, Pt). Pierce ${ }^{\text {TM }}$ Disposable columns (29925) were acquired from Thermo Fisher Scientific. Nylon $(0.45 \mu \mathrm{m})$ and glass microfiber $(1 \mu \mathrm{m})$ syringe filters (Whatman) were obtained from Sigma-Aldrich. Bovine serum albumin (>98\%), glycine (>99.5\%), sodium chloride $(\mathrm{NaCl})$ and Tris base ( $>99.9 \%$ ) were purchased from NZYTech (Lisbon, Pt). Polyethylene glycol (PEG) 8000, sodium hydrogen carbonate $\left(\mathrm{NaHCO}_{3}\right)$ and citric acid $(>99.5 \%)$ were supplied from Sigma-Aldrich. Sodium acetate anhydrous (99\%) was obtained from Applichem and glacial acetic acid was purchased from Scharlau. Hydrochloric acid 37\% (v/v) and ethanol $100 \%(\mathrm{v} / \mathrm{v})$ were acquired from Chem-lab. Methanol $99.9 \%(\mathrm{v} / \mathrm{v})$ and acetonitrile $99.9 \%(\mathrm{v} / \mathrm{v})$ were supplied from Merck (Lisbon, Pt). OTA immunoaffinity columns (OchraTest ${ }^{\mathrm{TM}} \mathrm{WB}$ ) were supplied by Vicam (Nixa, USA). Red wines were purchased from a local Portuguese store.

\subsection{Construction of BSA-agarose SPE columns}

BSA was immobilized in Cyanogen bromide-activated agarose according to the manufacturer's protocol. Briefly, the resin was swollen and washed with cold $0.001 \mathrm{M}$ hydrochloric acid to remove lactose and then washed with distilled water and $0.1 \mathrm{M} \mathrm{NaHCO}_{3} / 0.5 \mathrm{M} \mathrm{NaCl} \mathrm{pH} 8.3$ (coupling buffer). Between washing steps the resin was gently filtered in columns equipped with polyethylene disks of $30 \mu \mathrm{m}$ pore size to remove the supernatant. The resin was incubated with BSA overnight at $4^{\circ} \mathrm{C}$ under shaking. Then, the unreacted BSA was washed away with coupling buffer by filtration in the above mentioned columns, and the unreacted groups were blocked with $0.2 \mathrm{M}$ glycine $\mathrm{pH} 8.0$ for $2 \mathrm{~h}$ at room temperature. At last, the resin was extensively washed four times with $0.1 \mathrm{M} \mathrm{NaHCO}_{3} / 0.5 \mathrm{M} \mathrm{NaCl} \mathrm{pH} 8.3$ and $0.1 \mathrm{M}$ acetate buffer $\mathrm{pH} 4.0$ containing $0.5 \mathrm{M} \mathrm{NaCl}$. The resin was equilibrated in $0.01 \mathrm{M}$ Tris buffer $\mathrm{pH} 7.0$ before being packed into empty gravity flow SPE columns (volumes of $0.5,1.0$ and $1.5 \mathrm{~mL}$ were packed as needed). The amount of BSA immobilized was approximately $4 \mathrm{mg}$ per $\mathrm{mL}$ of resin. Agarose columns with no BSA immobilized and blocked with glycine were also produced following the same protocol.

\subsection{Preliminary evaluation of OTA's capture by BSA-agarose columns}

OTA solutions $\left(10 \mu \mathrm{g} \mathrm{L}^{-1}\right)$ were prepared in $0.1 \mathrm{M}$ citric acid-sodium citrate buffer $\mathrm{pH} 3.5,0.01 \mathrm{M}$ Tris buffer $\mathrm{pH} 7.0$, and 0.1 and $0.01 \mathrm{M}$ Tris buffer $\mathrm{pH}$ 8.0. The constructed BSA-agarose columns, containing $0.5 \mathrm{~mL}$ of resin, were equilibrated with $5 \mathrm{~mL}$ of buffer under study and loaded with $1 \mathrm{~mL}$ of OTA solution prepared in the same buffer. Afterwards, the column was washed with $5 \mathrm{~mL}$ of buffer and OTA eluted with $3 \mathrm{~mL}$ of methanol containing $1 \%(\mathrm{v} / \mathrm{v})$ of acetic acid. Throughout this procedure, each millilitre was saved separately, diluted 1:2 with HPLC mobile phase (acetonitrile/water/acetic acid (99/99/2, v/v/v)) and kept at $4{ }^{\circ} \mathrm{C}$ until OTA quantification by HPLC-FL. BSA was also assayed in each fraction to evaluate eventual leaks of protein during the procedure. The capacity of the columns to concentrate OTA was evaluated by applying $10 \mathrm{~mL}$ of OTA solution $\left(10 \mu \mathrm{g} \mathrm{L}^{-1}\right)$ prepared in $0.01 \mathrm{M}$ Tris $\mathrm{pH}$ 8.0. The influence of ethanol in OTA's capture was studied by loading $1 \mathrm{~mL}$ of this OTA solution containing $15 \%(\mathrm{v} / \mathrm{v})$ of ethanol. The equilibration, washing, and elution steps, and the collection, treatment and preservation of samples were executed as stated above. Negative controls were also performed using agarose columns in which BSA was not immobilized.

\subsection{Optimization of conditions for OTA's capture in wine}

A red wine sample $(5 \mathrm{~mL})$ was spiked with OTA $\left(10 \mu \mathrm{g} \mathrm{L}^{-1}\right)$ and diluted $1: 2$ or $1: 4$ with 0.1 or $0.3 \mathrm{M}$ Tris buffer $\mathrm{pH}$ 8.0. The wine/Tris solutions were applied into the BSA-agarose columns containing different resin volumes $(0.5,1.0$ or $1.5 \mathrm{~mL})$. The OTA extraction procedure was as follows: equilibration with $5 \mathrm{~mL}$ of $0.01 \mathrm{M}$ Tris buffer $\mathrm{pH} 7.0$, loading with 10 or $20 \mathrm{~mL}$ of wine/Tris solution (depending on dilution rate), washing with $5 \mathrm{~mL}$ of $0.01 \mathrm{M}$ Tris buffer $\mathrm{pH} 7.0$, and elution with $4 \mathrm{~mL}$ of methanol containing $1 \%(\mathrm{v} / \mathrm{v})$ of acetic acid. Samples processing was conducted as stated above.

\subsection{Validation of BSA-agarose columns for OTA determination in wine}

Wine was spiked with different concentrations of OTA $(0.05,0.5,1$, 2 and $3 \mu \mathrm{L} \mathrm{L}^{-1}$ ), diluted 1:4 with $0.1 \mathrm{M}$ Tris buffer $\mathrm{pH} 8.0$ (final $\mathrm{pH}$ approx. 7.2) and filtered through a $0.45 \mu \mathrm{m}$ nylon syringe filter (Whatman). SPE columns with $1.5 \mathrm{~mL}$ of BSA-agarose were equilibrated with $5 \mathrm{~mL}$ of $0.01 \mathrm{M}$ Tris buffer $\mathrm{pH} 7.0$, loaded with $20 \mathrm{~mL}$ of the wine/ buffer mixture, washed with $5 \mathrm{~mL}$ of $0.01 \mathrm{M}$ Tris buffer $\mathrm{pH} 7.0$ and eluted with $4 \mathrm{~mL}$ of methanol containing $1 \%(\mathrm{v} / \mathrm{v})$ of acetic acid. The eluate was then evaporated at $40{ }^{\circ} \mathrm{C}$ with a slight nitrogen flow and resuspended in $0.5 \mathrm{~mL}$ of HPLC mobile phase. The samples were preserved at $4{ }^{\circ} \mathrm{C}$ until OTA quantification by HPLC-FL. Two independent assays for each OTA concentration were performed.

\subsection{OTA determination in wine by immunoaffinity columns}

The determination of OTA in wine by IAC followed the AOAC Official Method 2001.01 (Visconti, Pascale, \& Centonze, 2001). Briefly, OTA-spiked wine samples prepared above $\left(0.05,0.5,1,2\right.$ and $\left.3 \mu \mathrm{g} \mathrm{L}^{-1}\right)$ were diluted $1: 2$ in $1 \%$ PEG $8000 / 5 \% \mathrm{NaHCO}_{3} \mathrm{pH} 8.3$ and filtered through a $1 \mu \mathrm{m}$ glass microfiber syringe filter (Whatman). 
Immunoaffinity columns OchraTest WB were loaded with $10 \mathrm{~mL}$ of this solution and then washed with $5 \mathrm{~mL}$ of $0.5 \% \mathrm{NaHCO}_{3} / 2.5 \% \mathrm{NaCl}$ and $5 \mathrm{~mL}$ of distilled water. OTA was eluted with $2 \mathrm{~mL}$ of methanol, which were evaporated at $40^{\circ} \mathrm{C}$ with a slight nitrogen flow and resuspended in $0.5 \mathrm{~mL}$ of HPLC mobile phase. The samples were also preserved at $4^{\circ} \mathrm{C}$ until OTA quantification by HPLC-FL. Two independent assays for each OTA concentration were performed.

\subsection{HPLC analysis}

OTA was quantified as described in Abrunhosa et al. (2014) using HPLC-FL with a system consisting of a Varian Prostar 210 pump, a Varian Prostar 410 autosampler, a Jasco FP-920 fluorescence detector and a Jones Chromatography 7971 column heater that was maintained at $30{ }^{\circ} \mathrm{C}$. This system was managed by a Varian 850-MIB data system interface and operated with the Galaxie chromatography software. The chromatographic separation was performed on a C18 reversed-phase YMC-Pack ODS-AQ analytical column $(250 \times 4.6 \mathrm{~mm}$ I.D., $5 \mu \mathrm{m})$ connected to a pre-column with the same stationary phase. Samples' elution was performed at a flow rate of $1.0 \mathrm{~mL} / \mathrm{min}$ with a mobile phase consisting of acetonitrile/water/acetic acid (99:99:2, v/v/v) previously filtered and degassed with a $0.2 \mu \mathrm{m}$ GHP membrane filter (Gelman). The injection volume was $50 \mu \mathrm{L}$ and the parameters used for OTA detection were: excitation $=333 \mathrm{~nm}$, emission $=460 \mathrm{~nm}$, Gain $=1000$. The calibration curve was prepared using a OTA commercial standard with certified concentration (34037-2ML-R, Sigma-Aldrich). Twelve standards with concentrations between $0.05 \mu \mathrm{g} \mathrm{L}^{-1}$ and $100.0 \mu \mathrm{g} \mathrm{L}^{-1}$ were prepared in mobile phase by serial dilution and analysed by HPLCFL three times each. The regression of the data delivered a linear fit: $Y=1392.076 \cdot X$ with a $\mathrm{R}^{2}=0.9999$.

\subsection{BSA determination}

BSA was determined using the Bradford assay-based method from Bio-Rad ( $\left.{ }^{\circ} 500-0002\right)$ following the microtiter plate protocol. Briefly, $10 \mu \mathrm{L}$ of each sample and $200 \mu \mathrm{L}$ of diluted dye reagent (1 part of concentrate dye reagent and 4 parts of distilled water) were pipetted into a 96-well microplate. After an incubation of $5 \mathrm{~min}$ at room temperature the plates were read at $595 \mathrm{~nm}$ in a microplate reader (Citation $^{\mathrm{TM}} 3$, Biotek ${ }^{\mathrm{TM}}$ ). A calibration curve with concentrations between 0.1 and $0.8 \mathrm{mg} \mathrm{mL}^{-1}$ of BSA was prepared.

\section{Results and discussion}

\subsection{Preliminary evaluation of OTA's capture by BSA-agarose columns}

The capture efficacy of the constructed BSA-agarose columns was first studied by extracting OTA from $10 \mu \mathrm{L} \mathrm{L}^{-1}$ solutions in Tris buffer (0.01 M, pH 7.0, and 0.1 and $0.01 \mathrm{M}, \mathrm{pH} 8.0$ ) and citric acid-sodium citrate buffer $(0.1 \mathrm{M}, \mathrm{pH} 3.5)$, in comparison with agarose columns without immobilized BSA (negative control).

As shown in Table 1, practically all OTA loaded onto the negative control was washed out in the flow-through $(30.8 \%)$ and washing steps (64.6\%), while in the BSA-agarose columns a high retention of OTA was attained, especially with $0.01 \mathrm{M}$ Tris $\mathrm{pH} 8.0$ and 7.0. In these cases, OTA loaded was only recovered in the elution steps $(114.7 \%$ and $113.9 \%$, respectively). These results indicate a strong interaction between OTA and BSA-agarose and the feasibility of this system to capture OTA from aqueous solutions in the $\mathrm{pH}$ range of 7.0 to 8.0. This result is in line with a previous study on the interaction of OTA with BSA, which revealed the influence of the $\mathrm{pH}$ over the formation of OTA-BSA complex (Chu, 1971). According to this author, at $\mathrm{pH} 7.0$ the complex is mostly complete and the interaction remains stable until $\mathrm{pH} 10.4$, above which it may dissociate. Furthermore, current studies on albumins-OTA interactions were successfully conducted at physiological $\mathrm{pH}$ 7.4 (Poór et al., 2014).
When $\mathrm{pH} 3.5$ was tested, although no OTA was detected in the flowthrough step, the mycotoxin was not adequately retained inside the column during the washing steps, since $78 \%$ of the initial OTA was washed out (Table 1). Thus, it can be assumed that acidic $\mathrm{pH}$ values do not favor a stable interaction between OTA and the BSA-agarose. This result is corroborated by data from literature, which suggest a weak OTA-BSA interaction at $\mathrm{pH}$ values below 4.0 (Uchiyama, Saito, \& Uchiyama, 1985). The $\mathrm{pH}$ of 3.5 was chosen in this work in regard of the natural $\mathrm{pH}$ of wine, which is typically between 2.9 and 3.8 (Obreque-Slier, Espinola-Espinola, \& Lopez-Solis, 2016), because it would allow to load directly wine into the columns. Nonetheless, the results obtained make impracticable to capture OTA directly from wine samples without any additional modification. Thus, further optimization at $\mathrm{pH} 3.5$ was not attempted.

On another hand, the improvement of OTA extraction at $\mathrm{pH} 8.0$ was quite straightforward. The reduction of the ionic strength of Tris buffer from 0.1 to $0.01 \mathrm{M}$ (elution recovery of $94 \%$ and $115 \%$, respectively), resulted in an improved interaction between OTA and the immobilized BSA as it allowed eliminating the small OTA losses (c.a. 4\%) occurring in the flow-through and washing steps (Table 1). The weakening of the binding of OTA to BSA by the ionic strength $(0-2.0 \mathrm{M} \mathrm{NaCl})$ has also been previously observed by Uchiyama et al. (1985). The addition of $15 \%(\mathrm{v} / \mathrm{v})$ ethanol to the buffer, to mimic the presence of this alcohol in real wine samples, had no substantial effect on the performance of the BSA-agarose column (elution recovery of $104 \%$; Table 1), thus indicating that this ethanol concentration does not interfere with the BSAOTA complex. It was also confirmed that the BSA-agarose column maintained its OTA recovery efficacy when changing the buffer $\mathrm{pH}$ to 7.0 (elution recovery of $114 \%$; Table 1 ). In addition, it was verified that the BSA-agarose column could extract and concentrate efficiently OTA from large buffer volumes (up to $10 \mathrm{~mL}$ ) and be reused many times without losing its efficacy, with no protein leaked during the extraction protocol, thus maintaining intact its recognition properties towards OTA (data not shown).

Altogether, these results indicate that the BSA-agarose system is suitable to set up an efficient protocol for the extraction of OTA from wine, provided that wine $\mathrm{pH}$ is adjusted to values between 7.0 and 8.0, and other fine-tuning optimizations be done. For example, it would be important to increase the concentration of OTA in final sample to ensure low detection limits and meet regulatory compliance.

\subsection{Optimization of conditions for OTA's capture in wine}

In order to develop the BSA-agarose system as a solid phase extraction (SPE) method for OTA determination in wine, recovery tests of OTA from wine samples spiked with known amounts of this mycotoxin were performed. These optimizations were conducted with $5 \mathrm{~mL}$ of wine to also assess the OTA enrichment capacity of BSA-agarose columns, as previously observed in the buffer tests. The best conditions for the full recovery of OTA in the elution step were pursued (Table 2).

Since previous experiments showed an unsatisfactory performance at $\mathrm{pH} 3.5$ and a good interaction at $\mathrm{pH} 7.0$ and 8.0, wine was initially diluted $1: 2$ with $0.3 \mathrm{M}$ Tris buffer at $\mathrm{pH} 8.0$ (Table 2 , run 1 ) to obtain a final $\mathrm{pH}$ within the optimal range of OTA binding ( $\mathrm{pH} 7-8)$. Nevertheless, this experiment delivered a poor OTA recovery (25\%), thus further modifications were introduced. Following, the wine was diluted 4 times in the same buffer (run 2) and the buffer molarity decreased to $0.1 \mathrm{M}$ (run 3), but yet OTA recoveries did not improve satisfactorily ( $17 \%$ and $67 \%$, respectively). Although a positive effect of decreasing the molarity by ten times was again observed, these recoveries were far below those of experiments conducted only in buffer. Possibly, some components of wine were affecting negatively the OTA-BSA interaction, since certain wine compounds such as resveratrol, tannins and anthocyanins can interact with BSA (Bourassa, Kanakis, Tarantilis, Pollissiou, \& Tajmir-Riahi, 2010; Liu et al., 2014; Wei, Xu, Zhang, Yang, \& Wang, 2018). This could be observed visually, since the columns retaining 
Table 1

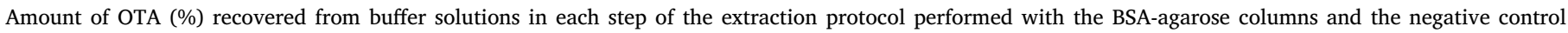
(agarose columns with no BSA immobilized).

\begin{tabular}{|c|c|c|c|c|c|c|c|}
\hline \multirow[t]{2}{*}{ Extraction step } & & \multirow{2}{*}{$\begin{array}{l}\text { Agarose column } \\
\text { (negative control) }\end{array}$} & \multicolumn{5}{|c|}{ BSA-agarose column } \\
\hline & & & $\begin{array}{l}0.1 \text { M Citrate } \\
\text { pH } 3.5\end{array}$ & $\begin{array}{l}0.1 \mathrm{M} \text { Tris } \\
\mathrm{pH} 8.0\end{array}$ & $\begin{array}{l}0.01 \mathrm{M} \text { Tris } \\
\mathrm{pH} 8.0\end{array}$ & $\begin{array}{l}0.01 \mathrm{M} \text { Tris } \\
\mathrm{pH} 8.0+\mathrm{EtOH}\end{array}$ & $\begin{array}{l}0.01 \mathrm{M} \text { Tris } \\
\mathrm{pH} 7.0\end{array}$ \\
\hline Flow-through & $1 \mathrm{~mL}$ & $30.8 \pm 20.6$ & $0.0 \pm 0.0$ & $0.3 \pm 0.6$ & $0.0 \pm 0.0$ & $0.0 \pm 0.0$ & $0.0 \pm 0.0$ \\
\hline \multirow[t]{3}{*}{ Column wash with buffer solution } & 1 st $\mathrm{mL}$ & $51.6 \pm 19.5$ & $1.8 \pm 0.0$ & $0.2 \pm 0.3$ & $0.0 \pm 0.0$ & $0.0 \pm 0.0$ & $0.0 \pm 0.0$ \\
\hline & 2nd mL & $10.7 \pm 3.9$ & $12.7 \pm 1.0$ & $0.1 \pm 0.2$ & $0.0 \pm 0.0$ & $0.0 \pm 0.0$ & $0.0 \pm 0.0$ \\
\hline & 3rd-5th mL & $2.3 \pm 1.7$ & $63.5 \pm 0.2$ & $3.2 \pm 2.9$ & $0.0 \pm 0.0$ & $0.0 \pm 0.0$ & $0.0 \pm 0.0$ \\
\hline \multirow[t]{3}{*}{ Column elution with acidified methanol } & 1 st $\mathrm{mL}$ & $2.2 \pm 3.8$ & $20.0 \pm 3.1$ & $82.2 \pm 10.3$ & $107.1 \pm 6.4$ & $102.0 \pm 0.8$ & $104.7 \pm 1.4$ \\
\hline & 2nd $\mathrm{mL}$ & $0.0 \pm 0.0$ & $0.4 \pm 0.3$ & $10.7 \pm 6.9$ & $7.3 \pm 5.2$ & $1.8 \pm 0.5$ & $9.2 \pm 0.7$ \\
\hline & 3rd mL & $0.0 \pm 0.0$ & $0.0 \pm 0.0$ & $4.4 \pm 2.3$ & $0.3 \pm 0.1$ & $0.0 \pm 0.0$ & $0.0 \pm 0.0$ \\
\hline Elution recovery & & $2.2 \pm 3.8$ & $20.4 \pm 2.8$ & $97.3 \pm 3.3$ & $114.7 \pm 2.7$ & $103.8 \pm 1.4$ & $113.9 \pm 2.1$ \\
\hline Total recovery & & $97.5 \pm 2.2$ & $98.3 \pm 1.7$ & $101.1 \pm 3.7$ & $114.7 \pm 2.7$ & $103.8 \pm 1.4$ & $113.9 \pm 2.1$ \\
\hline
\end{tabular}

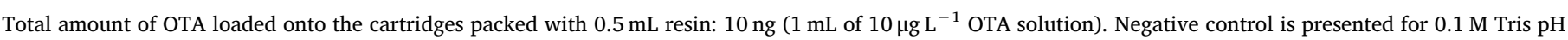
8.0. The values represent the average \pm standard deviations (SD) of two independent experiments.

most of the color components of red wine, which inclusively hampered columns reuse.

In order to eliminate the possible interference of wine components, the amount of BSA available for the capture of OTA was increased by increasing resin volumes in the column from $0.5 \mathrm{~mL}$ to 1.0 and $1.5 \mathrm{~mL}$. With this strategy, as shown in Table 2, OTA recoveries increased further until reaching $102 \%$ for the higher resin volume $(1.5 \mathrm{~mL})$ and the lower buffer molarity tested $(0.1 \mathrm{M})$.

\subsection{Validation of BSA-agarose SPE for OTA determination in wine}

To validate a clean-up method for OTA determination in wine by HPLC-FL based on the BSA-agarose system, OTA was extracted from red wine samples spiked with different concentrations of this mycotoxin in the range $0.05-3.0 \mu \mathrm{g} \mathrm{L}^{-1}$. The previously optimized protocol was used to operate the BSA-agarose columns (BAC) as described in Section 2.5. This protocol requires no wine pretreatment (e.g. tannins precipitation with poly(ethylene glycol), or extraction with aggressive organic solvents such as chloroform). Wine samples need only to be diluted 1:4 in $0.1 \mathrm{M}$ Tris buffer. At the end of the procedure, a 10-fold concentration of the wine-sample was obtained, which improved the limit of detection (LOD) and the limit of quantification (LOQ) to $0.017 \mu \mathrm{g} \mathrm{L}^{-1}$ and $0.051 \mu \mathrm{gL}^{-1}$, respectively. These limits are better than the ones reported in the literature for other SPE methods recently developed. For example, a method based on the stationary phases Amberlite IRC-50 and Lewatit CNP105 functionalized with a OTA-binding hexapeptide (Ser-Asn-Leu-His-Pro-Lys) presented LOD and LOQ values of 0.45 and $1.5 \mu \mathrm{g} \mathrm{L}{ }^{-1}$, respectively (Giovannoli et al., 2015). Furthermore, the performance of the developed BSA-based SPE method was superior to other SPE methods using MIP or aptamers as sorbents. Cao et al. (2013) used a commercial MIP (AffiniMIP ${ }^{\circledR}$, AFFINISEP, France) as SPE sorbent to optimize the determination of OTA in beer, wine, and grape juice by HPLC-FLD. Good recoveries of OTA from these food matrixes were reported at spiking levels of $0.1,2$, and $5 \mu \mathrm{g} / \mathrm{L}$ (ranging from 91.6 to $101.7 \%)$. However, the reported LOD and LOQ values $(0.025$ and $0.08 \mu \mathrm{g} / \mathrm{L}$, respectively) are about 1.5 -fold higher than those obtained in this work. LOD $(0.075 \mu \mathrm{g} / \mathrm{L})$ and LOQ $(0.225 \mu \mathrm{g} / \mathrm{L})$ values reported in a similar study that used another synthesized MIP to determine OTA in Italian red wines were 4.4-fold higher than those of the BSA-based SPE method (Giovannoli, Passini, Di Nardo, Anfossi, \& Baggiani, 2014). Additionally, Rhouati, Paniel, Meraihi, and Marty (2011) developed and tested an oligosorbent (aptamer) for the analytical determination of OTA in beer, reporting a LOD of $0.2 \mu \mathrm{g} / \mathrm{L}$, which is also far over the response obtained herein using albumin as sorbent $\left(0.017 \mu \mathrm{g} \mathrm{L}^{-1}\right)$.

The linearity of the method was evaluated by plotting OTA concentrations measured after extraction with the BAC method against the spiked OTA concentrations (Fig. 1A). As shown in Fig. 1A, an excellent linear relationship $\left(\mathrm{R}^{2}=0.9999\right)$ between OTA added to wine and OTA recovered can be observed. The linearity of the data was also confirmed by checking the random distribution of residuals around zero (Boqué, Maroto, Riu, \& Xavier Rius, 2002). This confirms that the method can be used within the working range of 0.05 to $3.0 \mu \mathrm{g} \mathrm{L}^{-1}$ of OTA. Also, high recoveries were obtained with the BAC method (97.9-107.0\%) (Table 3). Recovery rates are a form to measure the yield of the extraction, that means, the fraction of the analyte present in the sample that is still present in the final extract. The recovery rate for the BAC method is in accordance with the guidelines imposed by the European Commission that established the sampling and analytical methods for the official control of mycotoxins levels in foodstuffs (Commission Regulation (EC) No 401/2006), which determines that the recovery rates must be in the ranges of $50-120 \%$ and $70-110 \%$ for the concentrations below and above $1 \mu \mathrm{g} \mathrm{L}^{-1}$, respectively (EC, 2006).

A direct comparison with a reference method based on commercial immunoaffinity columns (IACs) was also performed by analyzing the wine samples used to validate the BAC method (Table 3). The limit of detection and quantification of this method were calculated and were of

Table 2

OTA recovered from wine $\left(10 \mu \mathrm{L}^{-1}\right.$ of OTA) with the BSA-agarose columns prepared with different resin volumes. Wine was diluted with buffers of different molarities at dilution factors of 1:2 or 1:4.

\begin{tabular}{|c|c|c|c|c|c|c|c|}
\hline Resin volume (mL) & Run Number & Wine dilution Buffer & Wine dilution factor & Final volume (mL) & OTA concentration $\left(\mu \mathrm{g} \mathrm{L}^{-1}\right)$ & Final $\mathrm{pH}$ & OTA Recovery (\%) \\
\hline \multirow[t]{3}{*}{0.5} & Run 1 & $0.3 \mathrm{M}$ Tris $\mathrm{pH} 8.0$ & $1: 2$ & 10 & 5 & 7.2 & 25 \\
\hline & Run 2 & $0.3 \mathrm{M}$ Tris $\mathrm{pH} 8.0$ & $1: 4$ & 20 & 2.5 & 7.9 & 17 \\
\hline & Run 3 & $0.1 \mathrm{M}$ Tris $\mathrm{pH} 8.0$ & $1: 4$ & 20 & 2.5 & 7.2 & 67 \\
\hline 1.0 & Run 4 & $0.3 \mathrm{M}$ Tris $\mathrm{pH} 8.0$ & $1: 2$ & 10 & 5 & 7.2 & 69 \\
\hline \multirow[t]{2}{*}{1.5} & Run 5 & $0.3 \mathrm{M}$ Tris $\mathrm{pH} 8.0$ & $1: 2$ & 10 & 5 & 7.2 & 88 \\
\hline & Run 6 & $0.1 \mathrm{M}$ Tris $\mathrm{pH} 8.0$ & $1: 4$ & 20 & 2.5 & 7.2 & 102 \\
\hline
\end{tabular}


(A)

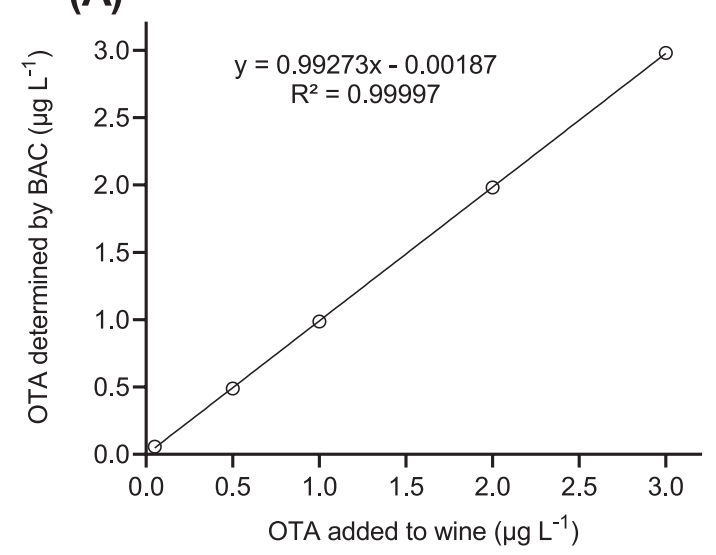

(B)

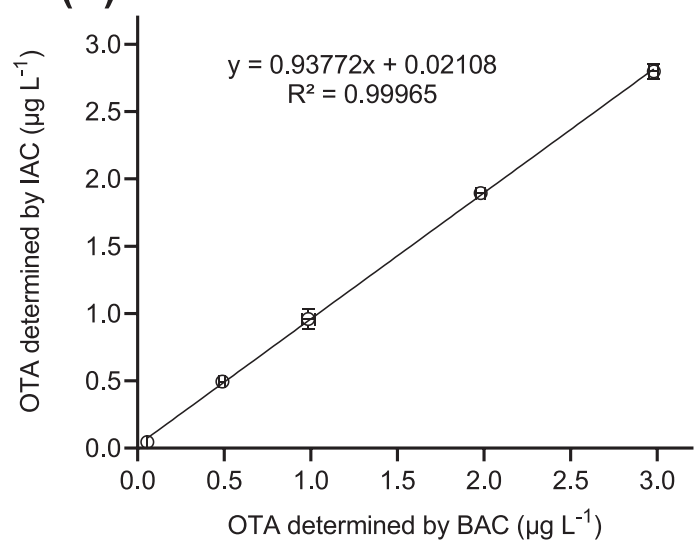

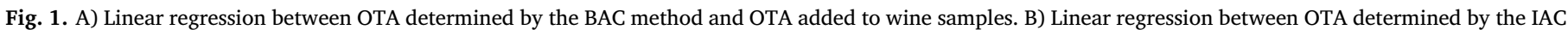
method and OTA determined by the BAC method.

Table 3

OTA extracted by the BAC and IAC methods from wine samples spiked with different OTA concentrations $\left(0.05\right.$ to $\left.3.0 \mu \mathrm{g} \mathrm{L}^{-1}\right)$ and respective recovery rates.

\begin{tabular}{lllll}
\hline $\begin{array}{l}\text { Spiked OTA } \\
\left(\mu \mathrm{L}^{-1}\right)\end{array}$ & BAC & \multicolumn{3}{c}{ IAC } \\
\cline { 2 - 5 } & $\begin{array}{l}\text { OTA extracted } \\
\left(\mu \mathrm{L} \mathrm{L}^{-1}\right)\end{array}$ & $\begin{array}{l}\text { Recovery rate } \\
(\%)\end{array}$ & $\begin{array}{l}\text { OTA extracted } \\
\left(\mu \mathrm{L} \mathrm{L}^{-1}\right)\end{array}$ & $\begin{array}{l}\text { Recovery rate } \\
(\%)\end{array}$ \\
\hline 0.05 & $0.05 \pm 0.01$ & $107.0 \pm 9.9$ & $0.05 \pm 0.01$ & $92.0 \pm 16.9$ \\
0.5 & $0.49 \pm 0.02$ & $97.9 \pm 3.6$ & $0.49 \pm 0.02$ & $99.1 \pm 3.5$ \\
1.0 & $0.99 \pm 0.04$ & $98.6 \pm 3.8$ & $0.96 \pm 0.08$ & $95.9 \pm 7.6$ \\
2.0 & $1.98 \pm 0.03$ & $99.1 \pm 1.3$ & $1.89 \pm 0.04$ & $94.7 \pm 1.9$ \\
3.0 & $2.98 \pm 0.03$ & $98.9 \pm 0.2$ & $2.80 \pm 0.06$ & $93.3 \pm 1.9$ \\
\hline
\end{tabular}

The values represent the average \pm standard deviations (SD) of two independent experiments.

$0.009 \mu \mathrm{g} \mathrm{L}^{-1}$ and $0.027 \mu \mathrm{gL}^{-1}$, respectively. Those values are slightly better than those of the BAC method, although recoveries with IACs (92.0-99.1\%) were slightly inferior to those of BAC method (97.9-107.0\%). Even that, they were also within the guidelines of the European Commission. The linear regression of OTA determined by the BAC method versus the IAC method also delivered a good fit $\left(\mathrm{R}^{2}=0.9997\right)$, which corroborates further the good performance of the developed BAC method (Fig. 1B).

The BSA-agarose method also delivered a satisfactory wine clean-up and a good selectivity for OTA determination. Nonetheless, the chromatograms obtained are not as clean as the ones obtained with IAC columns, showing that other compounds are bounding to the BSAagarose system. In Fig. 2, the chromatograms obtained by both methods for a wine sample spiked with $1 \mu \mathrm{L} \mathrm{L}^{-1}$ of OTA are presented as examples. In Fig. 2A, it can be observed small peaks of interferents near the OTA peak. Nonetheless, they do not pose any problem for OTA quantification because the chromatographic column can separate them from OTA under the operating conditions used. On another hand, the chromatograms of IAC method (Fig. 2B) shows a clearer chromatographic profile, with the peak corresponding to OTA eluting alone, which confirms the high specificity of the antibodies.

The binding performance of the BSA-agarose system confirms that this protein-based solid phase extraction is a viable alternative to conventional immunoaffinity clean-up (IAC), though its specificity is not as good as the one of IAC. Indeed, BSA can potentially replace antibodies as it is considerably cheaper and much easier to obtain. Due to its broad availability, and large binding spectrum range, BSA is frequently used as a blocking reagent of unspecific sites in several methodologies (e.g. ELISA). Giving the strong capacity of BSA to capture OTA, as demonstrated in this work, BSA is not an adequate blocking reagent for methodologies that intend to detect OTA, although it is recurrently used for this purpose (e.g. Zhang et al., 2018). The drawback of using BSA as a blocking agent is the possible enhancement or suppression of assays response due to the interference of OTA that binds to the protein, conducting to misleading results.

\subsection{Application of BSA-agarose SPE of OTA determination in wines}

Six Portuguese red wines were analyzed for the presence of OTA using both the BAC and IAC methods. As it can be seen in Table 4, OTA was detected in three out of six samples of red wine (wines 1, 2 and 4) by the BSA-agarose method and also by immunoaffinity. In these wines, the amount of OTA determined by the two methods was similar (Table 4). OTA was also detected in wine number three by the IAC method, although below the limit of quantification, but not by the BAC method. Since the detection limit of BAC is superior to that limit of IAC, OTA could not be detected by the BAC method in this wine. Nevertheless, these results confirm the good analytical performance and robustness of the BAC method, which is based on the natural binding affinity of BSA to OTA. The concentrations of OTA detected in all wines analyzed were very low (BAC method: average of $0.095 \mu \mathrm{g} \mathrm{L}^{-1}$ and median of $0.125 \mu \mathrm{g} \mathrm{L}^{-1}$; IAC method: average of $0.085 \mu \mathrm{g} \mathrm{L}^{-1}$ and median of $0.140 \mu \mathrm{g} \mathrm{L}^{-1}$ ) and far below the European legal limit of $2 \mu \mathrm{Kg}^{-1}$. This result agrees with other publications where low levels of OTA were also detected in Portuguese wines (Festas et al., 2000; Pena, Cerejo, Silva, \& Lino, 2010; Ratola, Martins, \& Alves, 2004). According to Abrunhosa et al. (2016), the levels found by several authors range from 0.002 to $2.4 \mu \mathrm{g} \mathrm{L}^{-1}$, with only two wines having OTA above the EU legal limit.

\section{Conclusions}

In this work, a new SPE method for the determination of OTA in wine was developed and validated. The method uses the ability of BSA, immobilized in agarose, to bind OTA at the $\mathrm{pH}$ range $7-8$. Its performance is comparable to methods based on immunoaffinity. Nevertheless, the chromatographic conditions are more demanding, since BSA is not as specific as the antibodies. The main advantage of this method, comparing with IAC, is its lower cost, since BSA is widely available at low prices.

\section{Declaration of Competing Interest}

The authors declare that they have no known competing financial interests or personal relationships that could have appeared to influence the work reported in this paper. 

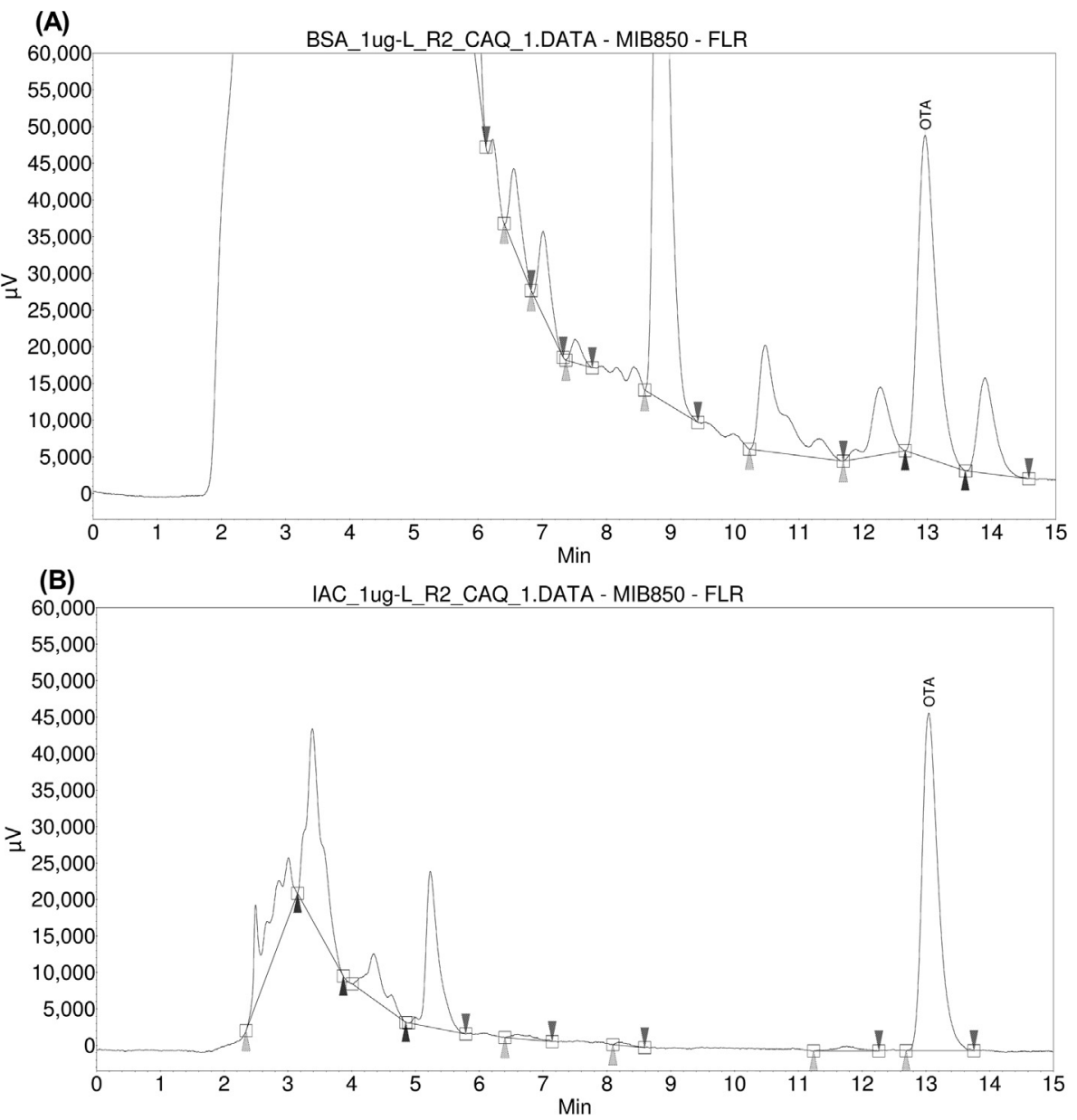

Fig. 2. HPLC-FL chromatograms of wine spiked with $1 \mu \mathrm{g} \mathrm{L}^{-1}$ of OTA analyzed by A) BAC method, B) IAC method.

Table 4

OTA analysis in six different Portuguese brands of red wine using BAC and IAC methods.

\begin{tabular}{lllll}
\hline $\begin{array}{l}\text { Wine } \\
\text { sample }\end{array}$ & Year & Region & $\begin{array}{l}\text { OTA determined by } \\
\text { BAC } \\
\left(\mu \mathrm{L} \mathrm{L}^{-1}\right)\end{array}$ & $\begin{array}{l}\text { OTA determined by } \\
\text { IAC } \\
\left(\mu \mathrm{g} \mathrm{L}^{-1}\right)\end{array}$ \\
\hline 1 & 2015 & Douro & 0.167 & 0.165 \\
2 & 2016 & Lisboa & 0.055 & 0.077 \\
3 & 2017 & Alentejo & - & 0.016 \\
4 & 2015 & Alentejo & 0.062 & 0.080 \\
5 & 2017 & Alentejo & - & - \\
6 & 2016 & Dão & - & - \\
\hline
\end{tabular}

* below LOQ; “-” not detected.

\section{Acknowledgements}

This study was supported by the Portuguese Foundation for Science and Technology (FCT) under the scope of the strategic funding of UID/ BIO/04469 unit and COMPETE 2020 (POCI-01-0145-FEDER-006684) and BioTecNorte operation (NORTE-01-0145-FEDER-000004) funded by the European Regional Development Fund under the scope of Norte2020 - Programa Operacional Regional do Norte. Luís Abrunhosa was supported by grant UMINHO/BPD/51/2015 from project UID/ BIO/04469/2013 financed by FCT/MEC (OE). Carla Oliveira was supported by the FCT grant SFRH/BPD/110640/2015.

\section{References}

Abrunhosa, L., Ines, A., Rodrigues, A. I., Guimaraes, A., Pereira, V. L., Parpot, P., ...
Venancio, A. (2014). Biodegradation of ochratoxin A by Pediococcus parvulus isolated from Douro wines. International Journal of Food Microbiology, 188, 45-52.

Abrunhosa, L., Morales, H., Soares, C., Calado, T., Vila-Cha, A. S., Pereira, M., \& Venancio, A. (2016). A review of mycotoxins in food and feed products in Portugal and estimation of probable daily intakes. Critical Reviews in Food Science and Nutrition, 56(2), 249-265.

Anfossi, L., Giovannoli, C., \& Baggiani, C. (2016). Mycotoxin detection. Current Opinion in Biotechnology, 37, 120-126.

Baggiani, C., Giovannoli, C., \& Anfossi, L. (2015). Man-made synthetic receptors for capture and analysis of ochratoxin A. Toxins, 7, 4083-4098.

Bazin, I., Tria, S. A., Hayat, A., \& Marty, J.-L. (2017). New biorecognition molecules in biosensors for the detection of toxins. Biosensors \& Bioelectronics, 87, 285-298.

Bennett, J. W., \& Klich, M. (2003). Mycotoxins. Clinical Microbiology Reviews, 16(3), 497-516.

Boqué, R., Maroto, A., Riu, J., \& Xavier Rius, F. (2002). Validation of analytical methods. Grasas y Aceites, 53(1), 2002.

Bourassa, P., Kanakis, C. D., Tarantilis, P., Pollissiou, M. G., \& Tajmir-Riahi, H. A. (2010) Resveratrol, genistein, and curcumin bind bovine serum albumin. The Journal of Physical Chemistry B, 114(9), 3348-3354.

Cao, J., Kong, W., Zhou, S., Yin, L., Wan, L., \& Yang, M. (2013). Molecularly imprinted polymer-based solid phase clean-up for analysis of ochratoxin A in beer, red wine, and grape juice. Journal of Separation Science, 36(7), 1291-1297.

Carter, D. C., \& He, X. M. (1990). Structure of human serum albumin. Science, 249(4966), 302-303.

Castegnaro, M., Tozlovanu, M., Wild, C., Molinie, A., Sylla, A., \& Pfohl-Leszkowicz, A. (2006). Advantages and drawbacks of immunoaffinity columns in analysis of mycotoxins in food. Molecular Nutrition \& Food Research, 50(6), 480-487.

Chauhan, R., Singh, J., Sachdev, T., Basu, T., \& Malhotra, B. D. (2016). Recent advances in mycotoxins detection. Biosensors and Bioelectronics, 81, 532-545.

Chu, F. S. (1974). A comparative study of the interaction of ochratoxins with bovine serum albumin. Biochemical Pharmacology, 23(6), 1105-1113.

Chu, F. S. (1971). Interaction of ochratoxin A with bovine serum albumin. Archives of Biochemistry and Biophysics, 147(2), 359-366.

EC. (2006). Commission Regulation (EC) No 401/2006. Laying down the methods of sampling and analysis for the official control of the levels of mycotoxins in foodstuffs. European Commission, L 70/12-L70/34

EC. (2016). Commission Regulation no 1881/2006 of 19 December 2006 setting maximum levels for certain contaminants in foodstuffs (consolidated version from 01/04/ 
2016). Official Journal of the European Union, L364/365-324.

Festas, I., Herbert, P., Silveira Santos, L., Cabral, M., Barros, P., \& Alves, A. (2000). Ochratoxin A in some Portuguese wines: Method validation and screening in Port Wine and Vinho Verde. American Journal of Enology and Viticulture, 51(2), 150-154.

Giovannoli, C., Passini, C., Di Nardo, F., Anfossi, L., \& Baggiani, C. (2014). Determination of ochratoxin A in Italian red wines by molecularly imprinted solid phase extraction and HPLC analysis. Journal of Agricultural and Food Chemistry, 62(22), 5220-5225.

Giovannoli, C., Passini, C., Volpi, G., Di Nardo, F., Anfossi, L., \& Baggiani, C. (2015). Peptide-based affinity media for solid-phase extraction of Ochratoxin A from wine samples: Effect of the solid support on binding properties. Talanta, 144, 496-501.

Huertas-Pérez, J. F., Arroyo-Manzanares, N., García-Campaña, A. M., \& Gámiz-Gracia, L. (2017). Solid phase extraction as sample treatment for the determination of Ochratoxin A in foods: A review. Critical Reviews in Food Science and Nutrition, 57(16), 3405-3420.

IARC. (1993). IARC Monographs on the Evaluation of Carcinogenic Risks to Humans, 56.

Il'ichev, Y. V., Perry, J. L., Ruker, F., Dockal, M., \& Simon, J. D. (2002). Interaction of ochratoxin A with human serum albumin. Binding sites localized by competitive interactions with the native protein and its recombinant fragments. ChemicoBiological Interactions, 141(3), 275-293.

Il'ichev, Y. V., Perry, J. L., \& Simon, J. D. (2002). Interaction of ochratoxin A with human serum albumin. Preferential binding of the dianion and $\mathrm{pH}$ effects. The Journal of Physical Chemistry B, 106(2), 452-459.

Koszegi, T., \& Poor, M. (2016). Ochratoxin A: Molecular interactions, mechanisms of toxicity and prevention at the molecular level. Toxins, 8(4), 111.

Liu, S., Guo, C., Guo, Y., Yu, H., Greenaway, F., \& Sun, M.-Z. (2014). Comparative binding affinities of flavonoid phytochemicals with bovine serum albumin. Iranian Journal of Pharmaceutical Research: IJPR, 13(3), 1019-1028.

Miraglia, M., \& Brera, C. (2002). Task 3.2.7 "Assessment of dietary intake of Ochratoxin A by the population of EU Member States": Directorate-General Health and Consumer Protection. Reports on Tasks for Scientific Cooperation.

Obreque-Slier, E., Espinola-Espinola, V., \& Lopez-Solis, R. (2016). Wine pH prevails over buffering capacity of human saliva. Journal of Agricultural and Food Chemistry, 64(43), 8154-8159.

Pena, A., Cerejo, F., Silva, L. J. G., \& Lino, C. M. (2010). Ochratoxin A survey in Portuguese wine by LC-FD with direct injection. Talanta, 82(4), 1556-1561.
Pichon, V., \& Combès, A. (2016). Selective tools for the solid-phase extraction of Ochratoxin A from various complex samples: Immunosorbents, oligosorbents, and molecularly imprinted polymers. Analytical and Bioanalytical Chemistry, 408(25), 6983-6999.

Poór, M., Li, Y., Matisz, G., Kiss, L., Kunsági-Máté, S., \& Kőszegi, T. (2014). Quantitation of species differences in albumin-ligand interactions for bovine, human and rat serum albumins using fluorescence spectroscopy: A test case with some Sudlow's site I ligands. Journal of Luminescence, 145, 767-773.

Ratola, N., Martins, L., \& Alves, A. (2004). Ochratoxin A in wines-assessing global uncertainty associated with the results. Analytica Chimica Acta, 513(1), 319-324.

Reddy, L., \& Bhoola, K. (2010). Ochratoxins-food contaminants: Impact on human health. Toxins, 2(4), 771-779.

Rhouati, A., Paniel, N., Meraihi, Z., \& Marty, J.-L. (2011). Development of an oligosorbent for detection of ochratoxin A. Food Control, 22(11), 1790-1796.

Ringot, D., Chango, A., Schneider, Y.-J., \& Larondelle, Y. (2006). Toxicokinetics and toxicodynamics of ochratoxin A, an update. Chemico-Biological Interactions, 159(1), $18-46$.

Şenyuva, H. Z., \& Gilbert, J. (2010). Immunoaffinity column clean-up techniques in food analysis: A review. Journal of Chromatography B, 878(2), 115-132.

Sorrenti, V., Di Giacomo, C., Acquaviva, R., Barbagallo, I., Bognanno, M., \& Galvano, F. (2013). Toxicity of ochratoxin a and its modulation by antioxidants: A review. Toxins, 5(10), 1742-1766.

Uchiyama, S., Saito, Y., \& Uchiyama, M. (1985). Protein-binding of ochratoxin A and its extractability from proteinous food. Journal of the Food Hygienic Society of Japan, 26(6), 651-657.

Visconti, A., Pascale, M., \& Centonze, G. (2001). Determination of ochratoxin A in wine and beer by immunoaffinity column cleanup and liquid chromatographic analysis with fluorometric detection: Collaborative study. Journal of AOAC International, 84(6), 1818-1827.

Wei, J., Xu, D., Zhang, X., Yang, J., \& Wang, Q. (2018). Evaluation of anthocyanins in Aronia melanocarpa/BSA binding by spectroscopic studies. AMB Express, 8(1), 72.

Zhang, T., Xing, B., Han, Q., Lei, Y., Wu, D., Ren, X., \& Wei, Q. (2018). Electrochemical immunosensor for ochratoxin A detection based on Au octahedron plasmonic colloidosomes. Analytica Chimica Acta, 1032, 114-121. 